\title{
IDENTIFICATION OF METHIONYL AND CYSTEINYL RESIDUES IN THE SUBSTRATE BINDING SITE OF CARBOXYPEPTIDASE $Y$
}

\author{
by \\ KLAUS BREDDAM and IB SVENDSEN \\ Department of Chemistry, Carlsberg Laboratory, \\ Gamle Carlsberg Vej 10, DK-2500 Copenhagen Valby
}

Keywords: Carboxypeptidase Y, chemical modification, amino acid sequence

\begin{abstract}
Chemical modification studies have previously indicated that the $S_{1}$ binding site of carboxypeptidase $Y$ contains a cysteinyl residue and that the $S_{i}$ binding site contains a methionyl residue (Carlsberg Res. Commun. 48, 9-19 (1983); 49, 535-554 (1984); 49, 627-638 (1984)). These studies also indicated that the active site contained an additional methionyl residue situated in an as yet unidentified position. In the present paper the positions of these amino acid residues has been identified in the amino acid sequence which has been revised on the basis of the nucleotide sequence (T. STEVENS, personal communications). The cysteinyl residue was identified as Cys-341 after alkylation with ${ }^{14} \mathrm{C}$-iodoacetic acid followed by separation of the peptides produced by cyanogen bromide cleavage and Edman degradation of the radioactive peptide. The methionyl residue situated in the Si binding site was identified as Met- 398 after alkylation with ${ }^{14} \mathrm{C}$-iodoacetamide, separation of the peptides produced by cyanogen bromide cleavage and thermal cleavage of the peptide containing the radioactivity. This assignment was confirmed by the failure of cyanogen bromide to cleave at the position of carboxypeptidase $Y$ in which this particular methionyl residue had been alkylated or oxidized. Using the same method the other methionyl residue in the active site was identified as Met-313.
\end{abstract}

\section{INTRODUCTION}

Chemical modification studies have indicated that a seryl and a histidyl residue are essential for the activity of CPD-Y from baker's yeast $(8,10)$ and consequently, the enzyme has been classified as a "serine carboxypeptidase" (EC 3.4.16.) (9). In addition, the active site contains a cysteinyl and a methionyl residue located at the $S_{1}$ and $S_{i}^{\prime}$ binding sites, respectively $(1,3,6,7)$, and an additional methionyl residue is presumably located in an as yet unidentified portion of the

active site (7). Chemical modifications of these amino acid residues have produced active derivatives with specificities which deviate from that of CPD-Y and it has been shown that these derivatives with advantage can be used in place of unmodified CPD-Y in certain processes concerning enzymatic peptide synthesis $(4,5,6)$. In the present communication the position of the cysteinyl residue and the two methionyl residues in the amino acid sequence is identified.

Abbreviations: CM-CPD-Y = CPD-Y modified with iodoacetic acid; CPD-Y = carboxypeptidase $\mathrm{Y}$; EDTA = ethylene diamine tetraacetic acid, sodium salt; IAA-CPD-Y $=$ CPD-Y modified with iodoacetamide; Met-SO-CPD$\mathrm{Y}=\mathrm{CPD}-\mathrm{Y}$ containing a single methionyl sulfoxide residue; $(\mathrm{Met}-\mathrm{SO})_{2}-\mathrm{CPD}-\mathrm{Y}=\mathrm{CPD}-\mathrm{Y}$ containing two methionyl sulfoxide residues; PTH = phenylthiohydantoin. The binding site notation for the enzyme is that of SCHECHTER and BERGER (19). Accordingly, the binding site for the C-terminal amino acid residue of the substrate is denoted $S_{i}$ and those for the amino acid residues in the amino-terminal direction away from the scissile bond are denoted $S_{1}, S_{2}, \ldots, S_{n}$. 


\section{MATERIALS AND METHODS}

\subsection{Materials}

CPD-Y was obtained from Carlsberg Biotechnology Ltd., Tagensvej 16, DK-2200 Copenhagen N, Biogel P-4 and P-60 were from Biorad, USA, iodoacetic acid and iodoacetamide were from Sigma, USA, phenacylbromide was from Fluka, Switzerland, and ${ }^{14} \mathrm{C}$-iodoacetamide and ${ }^{14} \mathrm{C}$-iodoacetic acid were from Amersham, England. Reagents and solvents used in the sequencer were obtained from Rathburn, England, except ethylacetate which was from Merck, W. Germany. All other chemicals and solvents were of analytical purity and obtained from Merck, W. Germany.

\subsection{Methods}

CM-CPD-Y with the cysteinyl residue located in the $S_{1}$ binding site alkylated with ${ }^{14} \mathrm{C}$-iodoacetic acid was prepared in the following way: $20 \mathrm{mg}$ lyophilized CPD-Y was dissolved in $1 \mathrm{ml} 0.1$ $\mathrm{M}-\mathrm{NaH}_{2} \mathrm{PO}_{4}, 6 \mathrm{M}$-guanidine hydrochloride, 10 mM-EDTA, pH 6.0 and $40 \mu 10.05 \mathrm{M}-{ }^{14} \mathrm{C}$-iodoacetic acid was added. Reaction time: $4 \frac{1}{2}$ hours. IAA-CPD-Y with the methionyl residue located in the $\mathrm{S}_{1}^{\prime}$ binding site alkylated by ${ }^{14} \mathrm{C}$-iodoacetamide was prepared in the following way (6): 6.2 $\mathrm{mg} / \mathrm{ml}$ CPD-Y, $0.18 \mathrm{M}$-iodoacetamide, 0.12 $\mathrm{M}-\mathrm{NaCl}, 0.03 \mathrm{M}-\mathrm{NaH}_{2} \mathrm{PO}_{4}, \mathrm{pH} 6.5,22^{\circ} \mathrm{C}$. Reaction time: 4 hours. Met-SO-CPD-Y with the methionyl residue located in the $\mathrm{S}_{1}^{\prime}$ binding site oxidized by $\mathrm{H}_{2} \mathrm{O}_{2}$ was prepared as previously described (7): $5.3 \mathrm{mg} / \mathrm{ml}$ CPD-Y, $0.1 \mathrm{M}$ $\mathrm{NaH}_{2} \mathrm{PO}_{4}, 0.19 \mathrm{M}-\mathrm{H}_{2} \mathrm{O}_{2}, \mathrm{pH} 4.75,22^{\circ} \mathrm{C}$. Reaction time: 2 h $20 \mathrm{~min}$. (Met-SO) ${ }_{2}-\mathrm{CPD}-\mathrm{Y}$ with two methionyl residues oxidized was prepared in the following way (7): $5.3 \mathrm{mg} / \mathrm{ml}$ CPD-Y, 0.1 M-sodium acetate, $0.19 \mathrm{M}-\mathrm{H}_{2} \mathrm{O}_{2}, \mathrm{pH} 4.75,22^{\circ} \mathrm{C}$. Reaction time: 8 hours. The reactions were terminated by separating the enzyme from rea- gent by gel filtration on Biogel P-4, equilibrated with water. The bed volume was $20-30$ fold the volume of the sample applied. IAA-CPD-Y, Met-SO-CPD-Y and (Met-SO) 2 -CPD-Y were separated from unmodified enzyme by affinity chromatography as previously described (7) and stored frozen in water.

CPD-Y and IAA-CPD-Y were oxidized with performic acid using the following procedure: $1.9 \mathrm{ml} 70 \% \mathrm{HCOOH}$ was mixed with $0.1 \mathrm{ml} 30 \%$ $\mathrm{H}_{2} \mathrm{O}_{2}$, left for two hours at room temperature and then placed on ice. $0.7 \mathrm{ml}$ of this reagent was then added to $10 \mathrm{mg}$ lyophilized enzyme and after two hours reaction at $0^{\circ} \mathrm{C} 30 \mathrm{ml}$ water was added followed by lyophilization.

Thiolysis of oxidized IAA-CPD-Y was carried out essentially as described by NAIDER and BOHAK (16): $7.5 \mathrm{mg}$ lyophilized oxidized IAACPD-Y was dissolved in $6.3 \mathrm{ml} 5 \mathrm{mM}-\mathrm{NaB}_{4} \mathrm{O}_{7}$, pH 9.0 and $80 \mu \mathrm{l}$ mercaptoethanol was added. After five hours reaction the mixture was dialyzed against water and lyophilized.

Unmodified CPD-Y, CM-CPD-Y, Met-SOCPD-Y, (Met-SO) ${ }_{2}-\mathrm{CPD}-\mathrm{Y}$ and IAA-CPD-Y were treated with $\mathrm{CNBr}$ in the following way: 7 mg lyophilized enzyme was dissolved in $980 \mu \mathrm{l}$ $70 \%$ formic acid and bubbled with nitrogen for $10 \mathrm{~min} .35 \mathrm{mg} \mathrm{CNBr}$ was added and the solution was purged with nitrogen. The reaction mixture was stirred in the dark for 20 hours at $22^{\circ} \mathrm{C}$ and subsequently, nitrogen was bubbled through the solution for three hours. The reaction mixtures were applied to a Biogel P-60 column $(1.6 \times 87$ $\mathrm{cm}$ ) equilibrated with $30 \%$ acetic acid.

Thermal cleavage of IAA-CPD-Y was performed by addition of boiling water to $1 \mathrm{mg}$ lyophilized IAA-CPD-Y and incubating the enzyme at $110^{\circ} \mathrm{C}$ for 70 min essentially as described by LAWSON et al. (13) and MARIANO et al. (14).

Cyanogen bromide fragments were identified

\footnotetext{
Figure 1. Complete amino acid sequence of CPD-Y based on amino acid sequence studies $(15,22)$ and nucleotide sequence studies (TOM STEVENS, Institute of Molecular Biology, University of Oregon, USA, personal communications, results to be published). The sequences as determined by the two different methods vary at four positions: His-149, Gly-150, Glu-278 and Asp-418 in the amino acid sequence are Gly-149, His-150, Tyr-278 and Gly-418 in the nucleotide sequence. Methionyl residues are underlined, the unblocked cysteinyl residue is indicated by SH and the reactive seryl residue by an asterix, and the residues to which carbohydrate is attached are marked with a diamond.
} 
K. BReddam \& I. Svendsen: Binding subsites of carboxypeptidase $Y$

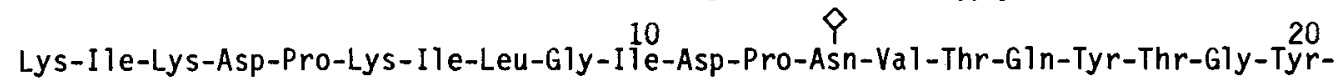
Leu-Asp-Val-Glu-Asp-Glu-Asp-Lys-His-Phe-Phe-Phe-Trp-Thr-Phe-Glu-Ser-Arg-Asn-AspPro-Ala-Lys-Asp-Pro-Val-I le-Leu-Trp-Leu-Asn-Gly-Gly-Pro-Gly-Cys-Ser-Ser-Leu-ThrGly-Leu-Phe-Phe-Glu-Leu-Gly-Pro-Ser-Ser-I le-Gly-Pro-Asp-Leu-Lys-Pro-Ile-Gly-AsnPro-Tyr-Ser-Trp-Asn-Ser-Asn-Ala-Thr-Val-I le-Phe-Leu-Asp-GIn-Pro-Val-Asn-Val-G1yPhe-Ser-Tyr-Ser-Gly-Ser-Ser-Gly-Val-Ser-Asn-Thr-Val-Ala-Ala-Gly-Lys-Asp-Val-TyrAsn-Phe-Leu-Glu-Leu-Phe-Phe-Asp-Gln-Phe-Pro-Glu-Tyr-Val-Asn-Lys-Gly-Gln-Asp-PheHis-I Ie-ATa-GTy-GIu-Ser-Tyr-Ala-His-Gly-Tyr-Il e-Pro-Val-Phe-ATa-Ser-GIu-Ile-Leu$\widehat{P}$
Ser-His-Lys-Asp-Arg-Asn-Phe-Asn-Leu-Thr-Ser-Val-Leu-Ile-Gly-Asn-Gly-Leu-Thr-AspPro-Leu-Thr-Gln-Tyr-Asn-Tyr-Tyr-Glu-Pro-Met-Ala-Cys-Gly-Glu-Gly-Gly-Glu-Pro-SerVal-Leu-Pro-Ser-Glu-Glu-Cys-Ser-Ala-Met-Glu-Asp-Ser-Leu-Glu-Arg-Cys-Leu-Gly-LeuIle-Glu-Ser-Cys-Tyr-Asp-Ser-Gln-Ser-Val-Trp-Ser-Cys-Val-Pro-Ala-Thr-Ile-Tyr-CysAsn-Asn-A1 a-Gln-Leu-Ala-Pro-Tyr-G1n-Arg-Thr-Gly-Arg-Asn-Val-Tyr-Asp-Il e-Arg-LysAsp-Cys-G1u-Gly-Gly-Asn-Leu-Cys-Tyr-Pro-Thr-Leu-G1n-Asp-I1e-Asp-Asp-Glu-Leu-AsnG]n-Asp-Tyr-Va]-Lys-Glu-Ala-Val-Gly-Ala-Glu-Val-Asp-His-Tyr-Glu-Ser-Cys-Asn-PheAsp-Ile-Asn-Arg-Asn-Phe-Leu-Phe-Ala-Gly-Asp-Trp-Met-Lys-Pro-Tyr-His-Thr-Ala-ValThr-Asp-Leu-Leü-Asn-G1n-Asp-Leu-Pro-Ile-Leu-Val-Tyr-Ala-Gly-Asp-Lys-Asp-Phe-Ile$S H$
$I$
Cys-Asn-Trp-Leu-Gly-Asn-Lys-Al a-Trp-Thr-Asp-Val-Leu-Pro-Trp-Lys-Tyr-Asp-G1 u-GluPhe-Ala-Ser-Gln-Lys-Val-Arg-Asn-Trp-Thr-Ala-Ser-Ile-Thr-Asp-Glu-Val-Ala-Gly-GluVal-Lys-Ser-Tyr-Lys-His-Phe-Thr-Tyr-Leu-Arg-Val-Phe-Asn-Gly-Gly-His-Met-Val-ProPhe-Asp-Val-Pro-Glu-Asn-Al a-Leu-Ser-Met-Val-Asn-Glu-Trp-Ile-His-Gly-Asp-Phe-Ser- 


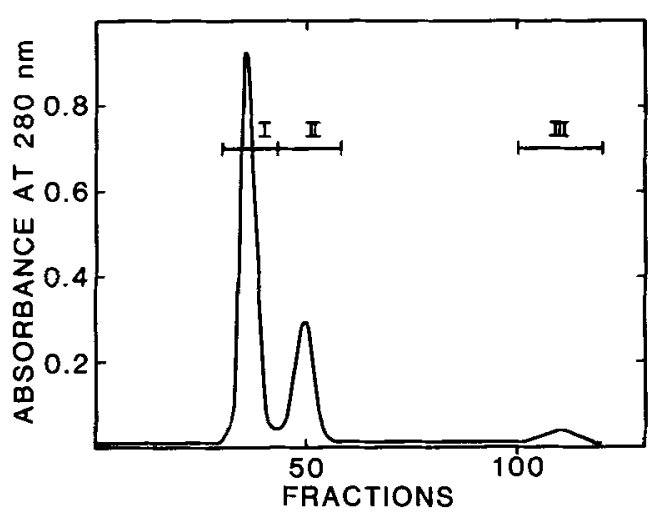

Figure 2. Gel filtration of the peptides obtained by cyanogen bromide cleavage of unmodified CPD-Y. Column: $1.6 \times 87 \mathrm{~cm}$ Biogel P-60, equilibrated with $30 \%$ acetic acid. Flow-rate: $9 \mathrm{ml} /$ hour. Fraction size: $1.7 \mathrm{ml}$. The fractions were pooled as indicated. The absorbance at $280 \mathrm{~nm}$ was measured.

by amino acid analysis and by the $\mathrm{N}$-terminal amino acid sequences as determined using a Beckman $890 \mathrm{C}$ liquid phase sequencer as previously described by JOHANSEN et al. (11). Identification of PTH amino acids was accomplished by high performance liquid chromatography as described by SVENDSEN et al. (21). Amino acid analysis was performed after acid hydrolysis for 24 hours in $6 \mathrm{M}-\mathrm{HCl}$ using a Durrum D 500 amino acid analyzer and ${ }^{14} \mathrm{C}$ measurements were performed by liquid scintillation using a Beckman scintillation counter, Model LS 3155 T.

\section{RESULTS}

\subsection{Cyanogen bromide fragments of CPD-Y}

CPD-Y contains five methionyl residues and their positions in the complete amino acid sequence as determined by protein sequencing $(15,22)$ and nucleotide sequencing (T.STEVENS, personal communications) is illustrated in Figure 1. Unmodified CPD-Y was cleaved with cyanogen bromide and the resultant peptide mixture was subjected to automated Edman degradation. The PTH amino acids present in the first five steps were consistent with the existence of equimolar amounts of the six peptides predicted from Figure 1. The six peptides could be separated in three fractions by chromatography on Biogel P-60 (Figure 2). Fraction I contained two peptides, 1-191 and 211-313 (Figure 1), fraction II only one peptide, 314-398, while fraction III contained three small peptides, 192-210, 399-410 and 411-421. The amino acid analysis of each of the fractions indicated that all the peptides were present in essentially equimolar amounts.

\subsection{Cyanogen bromide fragments of Met-SO- CPD-Y}

It is known that cyanogen bromide does not cleave peptide chains at methionyl residues which have been converted to methionyl sulfoxide (17). Thus, the peptide mixture obtained from cyanogen bromide cleavage of Met-SOCPD-Y with a single methionyl residue oxidized by treatment with $\mathrm{H}_{2} \mathrm{O}_{2}$ would be expected to contain only five peptides. Edman degradation of this mixture of peptides indicated the existence of equimolar amounts of all the peptides produced from unmodified CPD-Y with the exception of peptide 399-410. The peptides were separated in three fractions by chromatography on Biogel P-60 and the elution profile was similar to that in Figure 2. However, Edman degradation of the peptides in fraction III confirmed that peptide 399-410 was absent suggesting that no cleavage at Met-398 had taken place. This is supported by the fact that the amino acid composition of the peptide eluting in fraction II is consistent with the amino acid composition of peptide 314-410 and not with that of 314-398. These results indicate that Met-398 is specifically oxidized by $\mathrm{H}_{2} \mathrm{O}_{2}$.

\subsection{Cyanogen bromide fragments of (Met-SO) $)_{2}$-CPD-Y}

Edman degradation of the peptide mixture obtained by cyanogen bromide cleavage of (Met-SO) ${ }_{2}$-CPD-Y indicated that peptide 399. 410 was absent and that peptide 314-398 was present only in small quantities, i.e. below $10 \%$ of the amount of the $\mathrm{N}$-terminal fragment of CPD-Y. The peptides were separated in three fractions by chromatography on Biogel P-60 (Figure 3 ) and it is seen that the peak eluting in 


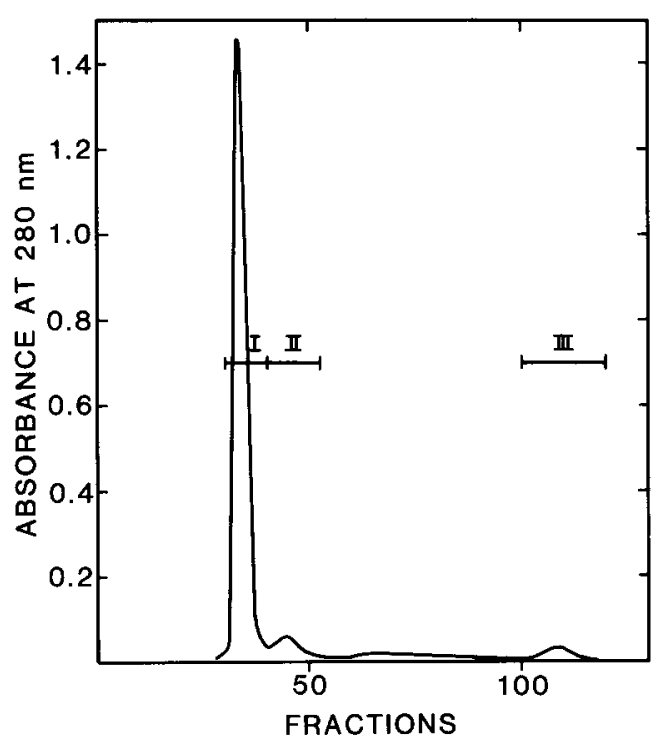

Figure 3. Gel filtration of the peptides obtained by cyanogen bromide cleavage of (Met-SO) ${ }_{2}$-CPD-Y. Column and conditions as listed in Figure 2.

fraction II is very small relative to that observed in Figure 2, suggesting that only very little cleavage had taken place at Met-313. Edman degradation of the peptides eluting in fraction III demonstrated the absence of peptide 399-410, suggesting that no cleavage had taken place at Met-398. These results indicate that it is Met398 and Met-313 which are oxidized in (Met$\mathrm{SO})_{2}$-CPD-Y.

\subsection{Cyanogen bromide fragments of IAA- CPD-Y}

Since alkylated methionyl residues are resistant towards oxidation (17) ${ }^{14} \mathrm{C}-\mathrm{IAA}-\mathrm{CPD}-\mathrm{Y}$ with a single methionyl residue alkylated by iodoacetamide (6) was oxidized with performic acid to convert unmodified methionyl residues to methionyl sulfone (see section 2.2). The alkyl group was then removed from the alkylated methionyl residue by treatment with mercaptoethanol (see section 2.2) followed by cyanogen bromide cleavage. Edman degradation of the resulting preparation indicated the $\mathrm{N}$-terminus of the enzyme and in addition, in equimolar amounts, an additional peptide with the $\mathrm{N}$-terminal sequence Val-Pro-Phe-Asp-Val-. When

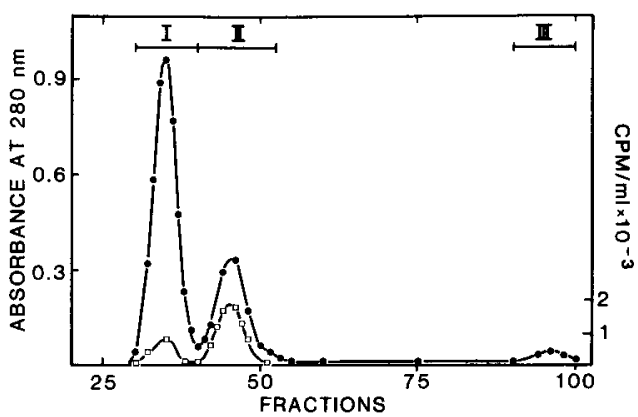

Figure 4. Gel filtration of the peptides obtained by cyanogen bromide cleavage of ${ }^{14} \mathrm{C}$-IAA-CPD-Y. Column and conditions as listed in Figure 2. Absorbance at $280 \mathrm{~nm}$ (-๑-๑) and radioactivity (- $\square-\square-)$ was measured. The radioactivity was expressed as $\mathrm{cpm} / \mathrm{ml}$ eluate.

unmodified CPD-Y was oxidized and treated with cyanogen bromide the Edman degradation indicated only the $\mathrm{N}$-terminus of the enzyme. These results suggest that it is Met-398 which is alkylated by iodoacetamide.

In a different series of experiments ${ }^{14} \mathrm{C}$-IAACPD-Y was treated with cyanogen bromide and the resulting peptides were then separated in three fractions by chromatography on Biogel P-60 (Figure 4). It is apparent that the predominant part of the radioactivity eluted in Fraction II indicating that the alkylated methionyl residue is located in the peptide with Lys-Pro-TyrHis-Thr- as the N-terminal sequence and the amino acid composition indicated that no cleavage had taken place at Met-398. To demonstrate conclusively the location of the alkylated methionyl residue it was utilized that peptides may be cleaved under mild conditions at alkylated methionyl residues by a mechanism similar to that responsible for the cleavage with cyanogen bromide $(13,14)$. When fraction II was boiled in water cleavage took place at Met-398 producing a new N-terminal sequence, Val-Pro-Phe-AspVal-. Thus, Met-398 is the site of reaction with iodoacetamide.

\subsection{Cyanogen bromide fragments of CM- CPD-Y}

CPD-Y treated with ${ }^{14} \mathrm{C}$-iodoacetic acid under denaturing conditions in order to carboxyme- 


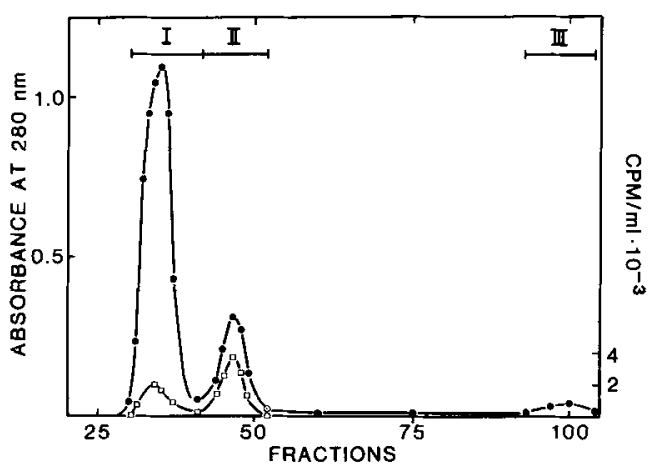

Fig. 5. Gel filtration of the peptides obtained by cyanogen bromide cleavage of ${ }^{14} \mathrm{C}-\mathrm{CM}-\mathrm{CPD}-\mathrm{Y}$. Column and conditions as listed in Figure 2. Absorbance at $280 \mathrm{~nm}(-\bullet-\bullet-)$ and radioactivity (- $\square-[-])$ was measured. The radioactivity was expressed as $\mathrm{cpm} / \mathrm{ml}$ eluate.

thylate the single cysteinyl residue was treated with cyanogen bromide and the resulting peptides separated in three fractions by chromatography on Biogel P-60 (Figure 5). The majority of the radioactivity eluted in fraction II and in addition, this fraction was the only one found to contain CM-Cys as determined by amino acid analysis. This shows that the single free cysteinyl residue is located in the cyanogen bromide fragment 314-398. This was already anticipated from the finding that this peptide contained only a single cysteinyl residue and separated from the other cyanogen bromide fragments during gel filtration (15). The cysteinyl residue in this fragment is located at position 341 (see Figure 1) and to confirm that this residue had been modified by iodoacetic acid, fragment 314-398 was subjected toautomated Edman degradation and theradioactivity of the PTH amino acid released in each step determined. It was found that all the radioactivity was attached to the $\mathrm{PTH}$ amino acid residue in step 28 and the HPLC identification showed a CM-Cys residue. Thus, the single cysteinyl residue of CPD-Y is located at position 341 .

\section{DISCUSSION}

It has previously been shown that chemical modification of two methionyl residues and a single cysteinyl residue in CPD-Y causes alter- ations in the enzymatic properties of the enzyme $(1,3,6,7)$ and hence, it may be inferred that these amino acid residues are located in the active site of the enzyme. In the present paper they have been identified as Met-313, Met-398 and Cys-341. Since the reactive seryl residue of CPD-Y is located at position 146 (22) it can be concluded that the active site is formed by amino acid residues which are remote from each other in the amino acid sequence.

Chymotrypsin $(12,18)$ and subtilisin (20) have been shown each to contain a methionyl residue which may be oxidized by $\mathrm{H}_{2} \mathrm{O}_{2}$ with alterations in the enzymatic properties as a consequence. However, the amino acid sequences around these methionyl residues exhibit no analogies with those around Met-313 and Met-398 in CPD-Y.

Numerous serine carboxypeptidases and two serine endopeptidases are known to contain a cysteinyl residue, suggesting that this group has a function, although apparently not in catalysis as indicated by the studies with CPD-Y $(1,3)$. The location of the cysteinyl residue has previously been identified only in thermitase from Thermoactinomyces vulgaris (2). However, the amino acid sequence around this amino acid residue exhibits no analogies with that around Cys-341 in CPD-Y, suggesting that their presence is due to a convergent evolution.

\section{ACKNOWLEDGEMENTS}

The authors gratefully acknowledge Professor MARTIN OTTESEN for his continued support and for revising the manuscript. Dr. TOM STEVENS, Institute of Molecular Biology, University of Oregon, USA is acknowledged for access to the unpublished nucleotide sequence and Mss Irene Simonsen, Pia BReddam and Lone SøRENSEN for excellent technical assistance.

\section{REFERENCES}

1. Bai, Y. \& R. Hayashi: Properties of the single sulfhydryl group of carboxypeptidase Y. Effects of alkyl and aromatic mercurials on activities towards various synthetic substrates. J. Biol. Chem. 254, 8473-8479 (1979)

2. Baudys, M., V. KostKa, G. Hausdorf, S. FitTKAU \& W.E. HOHNE: Amino acid sequence of the 
tryptic SH-peptide of thermitase, a thermostable serine proteinase from Thermoactinomyces vulgaris. Int. J. Peptide Protein Res. 22, 66-72 (1983)

3. BREDDAM, K.: Modification of the single sulfhydryl group of carboxypeptidase $Y$ with mercurials. Influence on enzyme specificity. Carlsberg Res. Commun. 48, 9-19 (1983)

4. BREDDAM, K., F. WidMer \& J.T. JohANSEN: Amino acid methyl esters as amine components in CPD-Y catalyzed peptide synthesis: Control of side reactions. Carlsberg Res. Commun. 48, 231237 (1983)

5. BReddam, K \& J.T. Johansen: Semisynthesis of human insulin utilizing chemically modified carboxypeptidase Y. Carlsberg Res. Commun. 49, 463-472 (1984)

6. BREDDAM, K.: Chemically modified carboxypeptidase $\mathrm{Y}$ with increased amidase activity. Carlsberg Res. Commun. 49, 535-554 (1984)

7. BREDDAM, K.: Modification of amino acid residues in the $S_{i}$ binding site. Carlsberg Res. Commun. 49, 627-638 (1984)

8. HAYASHI, R.,S. MOORE\& W.H.STEIN: Serine at the active site of yeast carboxypeptidase. J. Biol. Chem. 248, 8366-8369 (1973)

9. Hayashi, R., S. MoORE \& W.H. STEIN: Carboxypeptidase from yeast. Large scale preparation and application to $\mathrm{COOH}$-terminal analysis of peptides and proteins. J. Biol. Chem. 248, 2296-2302 (1973)

10. Hayashi, R., Y. BaI \& T. HaTA: Evidence for an essential histidine in carboxypeptidase $Y$. Reaction with the chloromethylketone derivative of benzyloxocarbonyl-L-phenylalanine. J. Biol. Chem. 250, 5221-5226 (1975)

11. Johansen, J.T., C. Overballe-Petersen, B. MARTIN, V. HaSEMANN \& I. SVENDSEN: The complete amino acid sequence of copper, zinc superoxide dismutase from saccharomyces cerevisiae. Carlsberg Res. Commun. 44, 201-217 (1979)
12. Koshland, D. E., D.N. Strumeyer \& W.J. Ray: Amino acids involved in the action of chymotrypsin. Brookhaven Symp. Biol. 15, 101 (1962)

13. Lawson, W.B., E. Gross, C.M. FoltZ \& B. WITKOP: Alkylation and cleavage of methionine peptides. J. Am. Chem. Soc. 84, 171 5-1718 (1962)

14. Mariano, P.S., G.I. Glover \& J.R. Petersen: Evidence for a stable conformation of phenacylchymotrypsin. Biochem. J. 171, 115-122 (1978)

15. Martin, B.M., I. Svendsen, T. Viswanatha \& J.T. JOHANSEN: Amino acid sequence of carboxypeptidase Y. I. Peptides from cleavage with cyanogen bromide. Carlsberg Res. Commun. 47, 1-13, 1982

16. NAIDER, F. \& Z. BOHAK: Regeneration of methionyl residues from their sulfonium salts in peptides and proteins. Biochemistry 11, 3208-3211 (1972)

17. Savige, W.E. \& A. Fontana: Interconversion of methionine and methionine sulfoxide. Meth. Enzymol. 47, 453-459 (1977), Eds. C.H.W. Hirs \& S. Timasheff, Academic Press

18. Schachter, H., K.A. Halliday \& G.H. Dixon: An alteration in the reactivity of chymotrypsin and trypsin towards hydrogen peroxide in the presence of specific substrates. J. Biol. Chem. 238, 31343136 (1963)

19. SCheChTER, I. \& A. Berger: On the size of the active site of proteases. I. Papain. Biochem. Biophys. Res. Commun. 27, 157-167 (1967)

20. Stauffer, C.E. \& D. Etson: The effect on subtilisin activity of oxidizing a methionine residue. J. Biol. Chem. 244, 5333-5338 (1969)

21. Svendsen, I., B. Martin \& I. Jonassen: Characteristics of hiproly barley. III. Amino acid sequences of two lysine-rich proteins. Carlsberg Res. Commun. 45, 79-85 (1980)

22. SVEndSEN, I., B.M. Martin, T. Viswanatha \& J.T. JOHANSEN: Amino acid sequence of carboxypeptidase Y. II. Peptides from enzymatic cleavages. Carlsberg Res. Commun. 47, 15-27 (1982)

Accepted by: H. KLENOW, E. LUND and S.O. ANDERSEN 